\title{
BASE HIDROGRÁFICA OTTOCODIFICADA NA ESCALA 1:25.000: EXEMPLO DA BACIA DO CÓRREGO ITAPIRANGA (SP)
}

\author{
Mateus Pedrucci Romanholi \\ Bacharel em Geografia, Universidade de São Paulo, São Paulo, Brasil \\ mateus.romanholi@usp.br \\ Alfredo Pereira de Queiroz Filho \\ Departamento de Geografia, Faculdade de Filosofia, Letras e Ciências Humanas, \\ Universidade de São Paulo, São Paulo, Brasil \\ aqueiroz@usp.br
}

\begin{abstract}
RESUMO
O gerenciamento dos recursos hídricos é uma atribuição institucional complexa e essencial. A delimitação, hierarquização e codificação da rede de drenagem e das bacias hidrográficas são elementos estruturais para sua gestão. O objetivo deste trabalho é elaborar e discutir o processo de criação de uma Base Hidrográfica Ottocodificada (BHO), na escala 1:25.000, do Córrego Itapiranga, localizada na região oeste do Estado de São Paulo. As ferramentas do sistema pgHydro, os programas ArcMap e QGIS, e as metodologias de delimitação de bacias hidrográficas sobre Modelos Digitais de Elevação (MDE) foram utilizadas. Para essa bacia de $26 \mathrm{~km}^{2}$, foram produzidas 107 Ottobacias (nível máximo 11). Constatou-se um considerável nível de complexidade operacional, mas os benefícios das consultas espaciais, decorrentes da codificação, e o contexto de integração de dados institucionais se mostraram muito promissores.
\end{abstract}

Palavras-chave: Ottocodificação. Bacia Hidrográfica. SIG.

\section{OTTOCODIFIED HYDROGRAPHIC DATASET AT 1:25,000 SCALE: EXAMPLE OF ITAPIRANGA CREEK BASIN (SP)}

\begin{abstract}
The management of water resources is a complex and essential institutional assignment. The delimitation, hierarchy and codification of the drainage network and the river basins are structural elements for its management. The objective of this work is to elaborate and discuss the process of creating an Ottocodified Hydrographic Base (OHB), at the 1: 25,000 scale of the Itapiranga Stream, located in the western region of the State of São Paulo. The tools of the pgHydro system, the ArcMap and QGIS programs, and the hydrographic basin delineation methodologies on Digital Elevation Models (DEM) were used. For this $26 \mathrm{~km}^{2}$ basin, 107 Ottobasins were produced (maximum level 11). A considerable degree of operational complexity was found, but the benefits of spatial queries from coding and the context of institutional data integration were very promising.
\end{abstract}

Keywords: Ottocodification. Watersheds. GIS.

\section{INTRODUÇÃO}

Bacia hidrográfica pode ser definida como a área drenada por um determinado rio ou sistema fluvial, que age em conjunto com as vertentes no transporte de material no interior e para fora da bacia (CHRISTOFOLETTI, 1980). Para Coelho Netto (1998), bacia hidrográfica é um sistema aberto aos fluxos de energia e matéria, cujas entradas são representadas pela precipitação atmosférica e forças tectônicas subjacentes e, as saídas, pela perda de água, sedimentos e materiais solúveis. Conforme Mattos e Perez Filho (2004), uma bacia hidrográfica não pode ser compreendida pelo estudo isolado de cada um de seus componentes. Sua estrutura, funcionamento e organização são produto das suas inter-relações, e a análise isolada desses componentes não permite compreender o funcionamento do sistema (bacia hidrográfica) enquanto unidade organizada complexa.

$\begin{array}{llllll}\text { Caminhos de Geografia } & \text { Uberlândia - MG } & \text { v. 19, n. } 68 & \text { Dez/2018 } & \text { p. 46-60 } & \text { Página } 46\end{array}$


As propriedades morfométricas e morfológicas das bacias hidrográficas são de grande interesse para a geomorfologia, assim como a caracterização e a hierarquização da rede de rios e canais, compreendida como um conjunto de segmentos de drenagem conectados por suas confluências (HORTON, 1945; STRAHLER, 1952; STRAHLER, 1957; SHREVE, 1966).

A delimitação, hierarquização e codificação de bacias hidrográficas e da rede de drenagem são essenciais ao gerenciamento das águas superficiais e subsuperficiais (SINGH et al., 2014; ELBEIH, 2015), na modelagem de processos erosivos, de dispersão de nutrientes e poluentes (BONHAM-CARTER et al., 1987; UZEIKA et al., 2012) e para estudos hidrológicos relacionados à altitude do terreno, declividade das vertentes, características dos solos, tipos de usos da terra, precipitação e escoamento superficial (SILVA e OLIVEIRA, 1999; PISSARRA et al., 2008).

Para o gerenciamento dos recursos hídricos, no atual contexto de desenvolvimento tecnológico, é fundamental estabelecer a topologia da rede hidrográfica e das bacias de drenagem. De acordo com Elull e Haklay (2006), a topologia pode ser definida como estudo das propriedades dos objetos, tais como adjacência, conectividade e continência. Embora seja muito utilizada pelos usuários dos Sistemas de Informações Geográficas, sua origem é antiga e está associada à Euler, que em 1736 resolveu o problema das Pontes de Konigsberg (atual Calinigrado, exclave russo no mar Báltico).

Quando aplicada à hidrografia, a topologia permite definir as relações espaciais entre os rios, como, por exemplo, a relação montante/jusante, e possibilita análises setorizadas, como as de precipitação e vazão (JAGER e VOGT, 2010). Sob essa perspectiva, metodologias tradicionais de hierarquização de drenagem (HORTON, 1945; STRAHLER, 1952; STRAHLER, 1957; SHREVE, 1966) apresentam limitações, pois não permitem a atribuição de identificadores únicos aos seus componentes nem a extração de informações espaciais da rede de drenagem (VOGT et al., 2007).

No Brasil, a metodologia de Otto Pfafstetter foi adotada para a codificação oficial de bacias hidrográficas e cursos d'água (PFAFSTETTER, 1989; VERDIN e VERDIN 1999; BRASIL, 2002). A codificação de Pfafstetter permite a consulta de informações topológicas da rede sem a necessidade de visualização gráfica (TEIXEIRA, 2012) e se adapta, sem perda de informação, às mudanças de escala e às inserções de novos elementos na rede. Essa funcionalidade permitiu que fosse aplicada, com pequenas modificações, em bacias alemãs e austríacas (VOGT et al., 2007; FÜRST e HÖRHAN, 2009; JAGER e VOGT, 2010).

A primeira versão da Base Hidrográfica Ottocodificada (BHO) foi elaborada em 2006. A base hidrográfica vetorial do mapeamento oficial brasileiro, na escala ao milionésimo, foi adotada. Posteriormente, Souza et al. (2011) e Luiz e Faria (2013) apresentaram trabalhos discutindo, respectivamente, a elaboração de uma BHO na escala 1:50.000, para o Estado do Paraná, e nas escalas 1:50.000 e 1:100.000, para o Estado de Minas Gerais, com o uso de Modelos Digitais de Elevação (MDEs). Esses trabalhos ressaltaram as dificuldades em processar computacionalmente o grande volume de dados das respectivas escalas, e a limitação operacional de 2GB de tamanho de arquivo, imposta pelo gerenciador de banco de dados utilizado pelas rotinas de codificação.

O projeto pgHydro (pghydro.org), em desenvolvimento na Agência Nacional de Águas (ANA) - desde 2012, visava criar um banco de dados relacional espacial para gerenciar os objetos hidrográficos que compõem o banco de dados brasileiro de recursos hídricos. O projeto possui um conjunto de ferramentas, - pgHydro Tools, que auxilia nas etapas de codificação dos segmentos de drenagem e bacias hidrográficas, de acordo com a metodologia de Pfafstetter, e utiliza funções recursivas e algoritmos de roteamento no banco de dados open-source PostgreSQL (TEIXEIRA, 2012; TEIXEIRA et al., 2013). Esse desenvolvimento superou as limitações de processamento e de armazenamento da construção de BHOs, nas escalas 1:50.000 e 1:100.000, mencionadas por Souza et al. (2011) e Luiz e Faria (2013) e colaborou para disseminar o processo com outras partes interessadas (TEIXEIRA et al., 2013).

Nesse contexto, o objetivo deste trabalho é elaborar uma BHO, na escala 1:25.000, da bacia do Córrego Itapiranga, localizada na região oeste do Estado de São Paulo, utilizando as ferramentas do pgHydro e metodologias de delimitação de bacias hidrográficas, a partir de Modelos Digitais de Elevação (MDEs), e abordar sua inserção no contexto tecnológico institucional.

\section{OTTOCODIFICAÇÃO}

A codificação de Otto Pfafstetter, proposta pelo engenheiro homônimo, em 1989, é a codificação oficial de bacias hidrográficas no Brasil (ANA, 2012). Este processo hierárquico começa pelos maiores rios de uma determinada bacia, em uma escala cartográfica pequena. Nos níveis posteriores, codifica a rede de

$\begin{array}{llllll}\text { Caminhos de Geografia } & \text { Uberlândia - MG } & \text { v. 19, n. } 68 & \text { Dez/2018 } & \text { p. 46-60 } & \text { Página } 47\end{array}$


drenagem em escalas progressivamente mais detalhadas, até que todos os trechos da rede hidrográfica tenham sido codificados. Em cada nível, um dígito é acrescentado ao código. O resultado é uma estratificação decorrente do grau de detalhamento da referida rede. Quanto maior o detalhamento, mais níveis serão necessários para codificar e, em decorrência, mais dígitos terão os códigos da Ottocodificação.

Suas principais vantagens são: 1) hierarquização da rede de drenagem, 2) topologia da rede embutida no código, 3) aplicação global e 4) fácil implantação computacional e boa interação com Sistemas de Informação Geográfica (SIGs). Os procedimentos de Pfafstetter para codificar as bacias, extraídos do Manual de Topologia Hídrica da Agência Nacional de Águas (ANA, 2006), estão resumidos a seguir, e seu exemplo pode ser visualizado na Figura 1:

- O curso d'água principal de uma bacia sempre é o que tem a maior área de contribuição de montante;

- A partir da identificação do curso d'água principal, codificam-se suas bacias afluentes por área de contribuição;

- As quatro maiores bacias afluentes recebem códigos pares (ex.: 2, 4, 6, etc.), atribuídos de jusante para montante;

- As interbacias recebem códigos ímpares. A da foz é a de número 1;

- A interbacia entre as bacias 2 e 4 recebe o valor 3 , e assim por diante, até a última bacia de montante, que recebe o número 9;

- Caso haja bacias internas, a maior recebe o código "0" e todas as outras bacias internas são incorporadas em alguma bacia ou interbacias próximas.

Figura 1: Exemplo da codificação de Otto Pfafstetter.

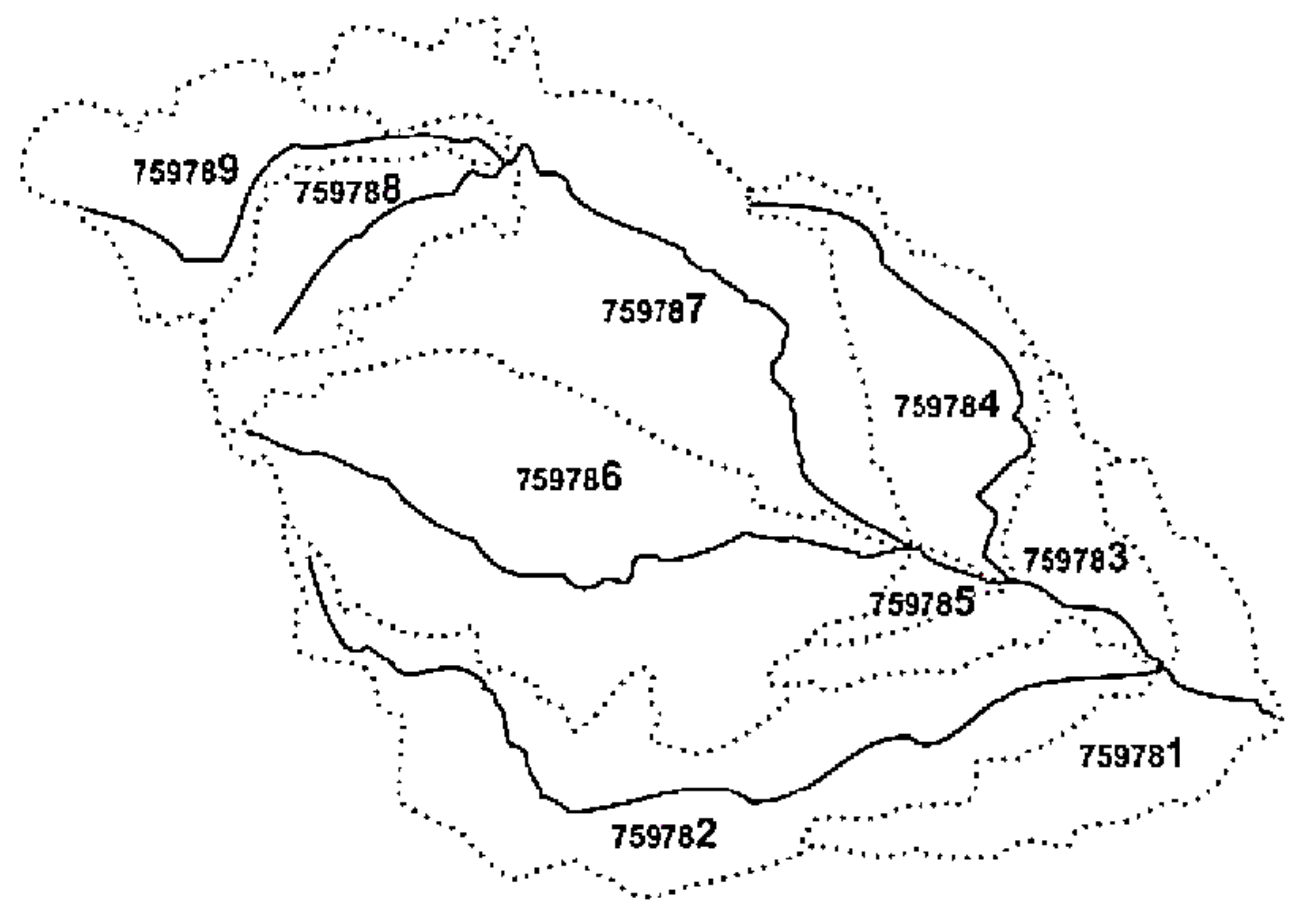

Fonte: Agência Nacional de Águas - ANA (2006).

Dentre as limitações da Ottocodificação, Teixeira (2012) cita a necessidade de representação da rede na forma de grafo anti-arborescente sem interrupções e a dificuldade de representar massas d'água e rios de margem dupla, fozes em delta, igarapés e outras morfologias de canais mais complexos. 
Para superar as referidas limitações e difundir o processo de construção da BHO, os trabalhos de Teixeira (2012) e Teixeira et al. (2013) propuseram a adoção de softwares livres para a validação da base cartográfica, construção e codificação dos objetos que integram a BHO. O projeto pgHydro, desenvolvido por esses autores, divide-se em: pgHydro Schema, que realiza a modelagem dos objetos da BHO no banco de dados espacial PostgreSQL/PostGIS, e pgHydro Tools, cujas funções de banco de dados são responsáveis pela validação topológica e codificação da base hidrográfica. Softwares livres de geoprocessamento, como o QGIS, podem ser utilizados nas etapas de edição vetorial da base e acesso ao banco de dados.

Para identificar o curso d'água principal de uma bacia, a metodologia de Pfafstetter considera os segmentos com maior descarga anual. Adota a área total de drenagem de montante de cada confluência, conforme a rede é percorrida em sentido contrário ao fluxo d'água, a partir da foz (PFAFSTETTER, 1989).

O processo de construção de uma BHO depende da correta extração de feições topográficas, frequentemente realizada a partir de Modelos Digitais de Elevação (MDEs). Sua utilização possibilita maior precisão no cálculo da área de cada bacia e melhor coerência entre a rede de segmentos de drenagem e as bacias hidrográficas correspondentes. A construção do chamado Modelo Digital de Elevação Hidrologicamente Consistente (MDEHC) é necessário para subsidiar as análises hidrológicas mais avançadas, pois consideram a superfície da bacia de modo contínuo e os elementos nela contidos (TEIXEIRA, 2012).

Diversos pesquisadores desenvolveram metodologias para a extração de feições topográficas dos MDEs e enfatizaram a identificação de canais de drenagem e de linhas de cumeada (PEUCKER e DOUGLAS, 1975; O'CALLAGHAN e MARK, 1984; JENSON, 1985; SEEMULLER, 1989). Um procedimento usual baseia-se no preenchimento de depressões que impedem o fluxo superficial contínuo e a posterior determinação da direção do fluxo na superfície do modelo. Isso permite quantificar o total de células de montante que contribuem para o fluxo que se acumula em cada célula da grade. A esses valores são aplicados limiares que definem se uma célula será caracterizada como drenagem ou não (sobre limiares de fluxo acumulado, consultar SANTOS e SHIRAIWA (2012)). Células que não recebem contribuição de montante são caracterizadas como divisores de bacias (O'CALLAGHAN e MARK, 1984; JENSON e DOMINGUE, 1988; JENSON, 1991).

Com a crescente disponibilidade de MDEs de alta resolução (entre 5 e 10 metros) - e até mesmo de 1 a 2 metros, derivados de dados Light Detection And Ranging (LiDAR), foram desenvolvidos algoritmos para ajustes hidrológicos (rompimento de depressões). São utilizadas também soluções híbridas, em conjunto com algoritmos de preenchimento, uma vez que impõem menos alterações ao MDE (MARTZ e GARBRECHT, 1999; LINDSAY e CREED, 2005; LINDSAY e DHUN, 2015; LINDSAY, 2016).

Outro aspecto relevante é o correto posicionamento de pontos exutórios sobre as células de drenagem, principalmente aqueles que são derivados de fontes externas ao MDE, como os obtidos por coordenadas de campo, derivados da hidrografia vetorial e das estações fluviométricas. De acordo com Lindsay et al. (2008), a acurácia dos pontos exutórios sobre células que representam segmentos de drenagem é determinante no processo de delimitação das bacias hidrográficas, pois pontos exutórios localizados incorretamente podem dar origem a bacias totalmente distintas.

\section{MATERIAIS E MÉTODOS}

A síntese da metodologia deste estudo de caso está ilustrada na Figura 2. Foi extraída a partir dos estudos de Silva et al. (2007), Gomes e Barros (2011); Souza et al. (2011); Teixeira (2012); Luiz e Faria, (2013). As duas etapas principais são: construção e validação da base cartográfica de trechos de drenagem e bacias hidrográficas, e inserção da base cartográfica no banco de dados, para executar as funções de codificação.

A base hidrográfica vetorial na escala 1:25.000 foi cedida pelo Instituto Geográfico e Cartográfico (IGC) do Estado de São Paulo. Foi elaborada a partir de restituição fotogramétrica utilizando imagens aéreas de 2010, com resolução espacial de 0,45 metro.

O MDE utilizado, referente à folha de índice SF-22-Y-B-II-1-NO, também cedido pelo IGC, possui resolução espacial de 5 metros e foi gerado a partir da correlação de pares de imagens estereográficas, com edição do terreno para eliminar a vegetação e as edificações.

$\begin{array}{llllll}\text { Caminhos de Geografia } & \text { Uberlândia - MG } & \text { v. 19, n. } 68 & \text { Dez/2018 } & \text { p. 46-60 } & \text { Página } 49\end{array}$


Figura 2: Fluxograma metodológico

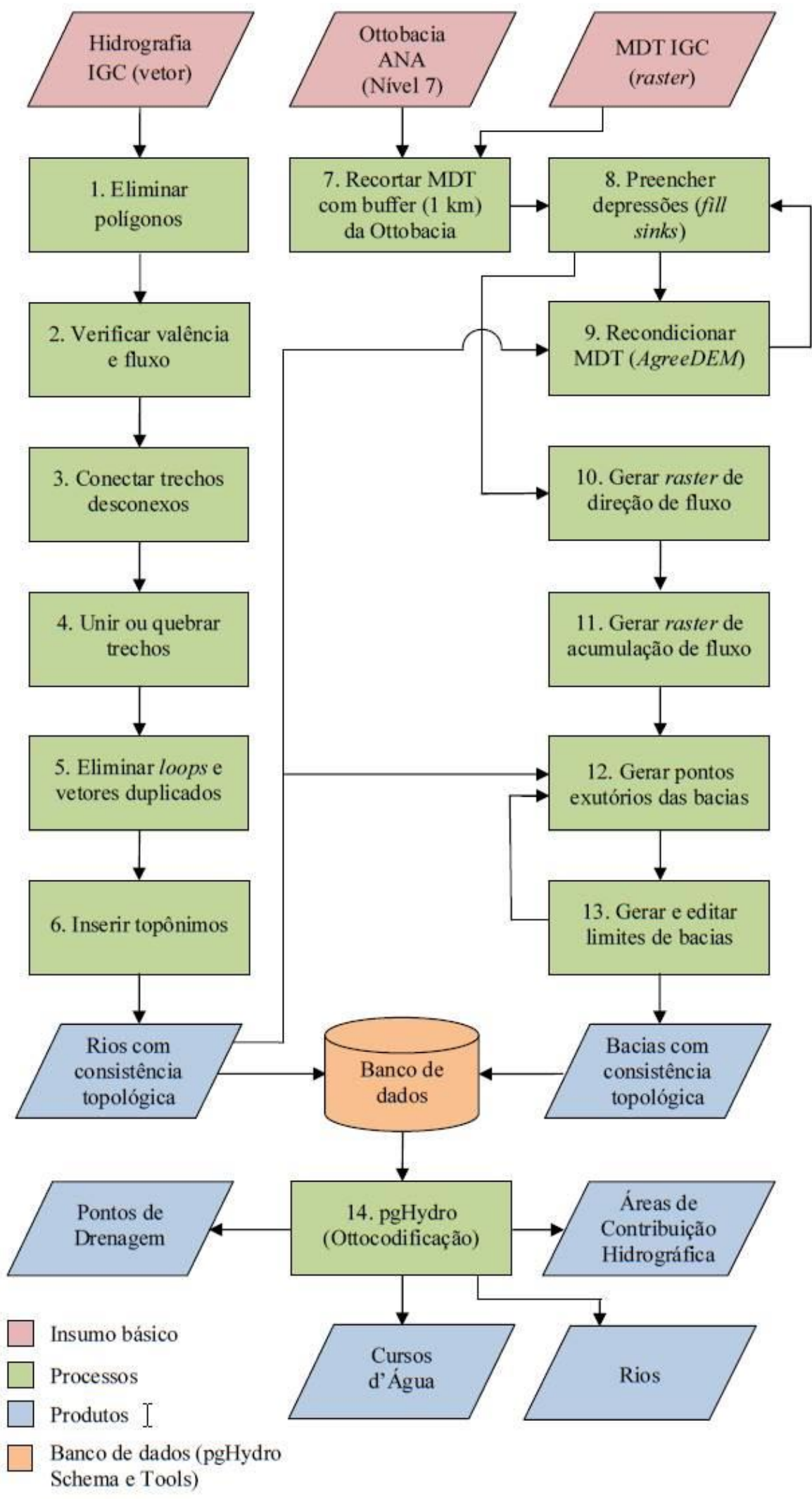

Fonte: Autores 
A área de estudo compreende a bacia do Córrego Itapiranga, localizada no oeste do Estado de São Paulo, no município de Marabá Paulista, distante cerca de $650 \mathrm{~km}$ da cidade de São Paulo (Figura 3). A área da bacia é de aproximadamente $26 \mathrm{~km}^{2}$ e o córrego se estende por cerca de 8 $\mathrm{km}$.

Figura 3: Área de estudo (Bacia do Córrego Itapiranga).
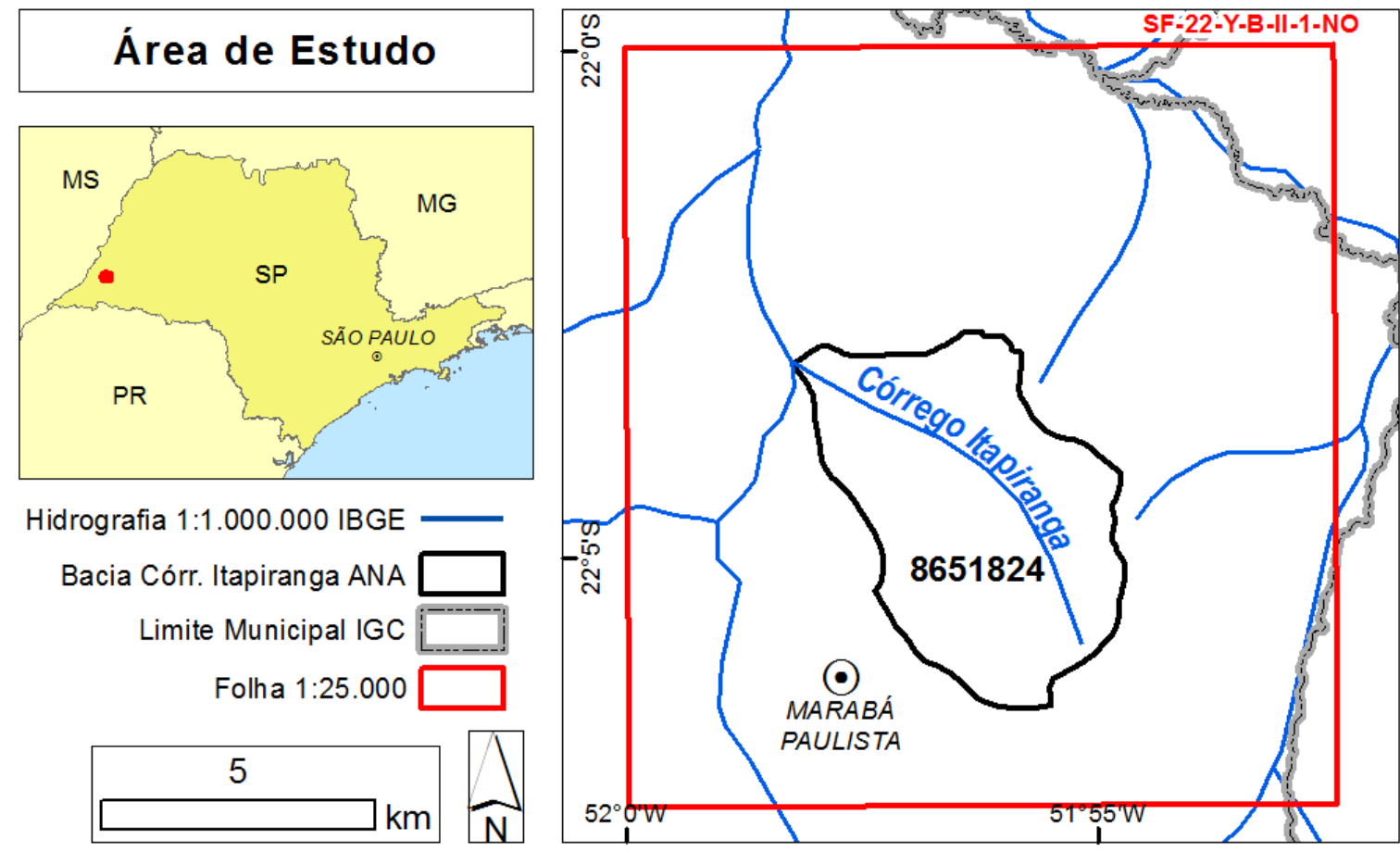

Fonte: Autores

\section{Validação da base cartográfica}

A validação topológica da rede hidrográfica foi executada no software ArcMap, versão 10.2.2, antes da inserção no banco de dados. Os dados vetoriais e raster utilizaram a projeção UTM (Fuso 22 Sul) e datum SIRGAS 2000.

Também foram executadas as etapas: eliminação de polígonos (rios de margem dupla, lagos, etc.); verificação de valência e fluxo; correção de interrupções na rede de drenagem; união ou quebra de trechos; eliminação de loops e vetores duplicados com ferramentas de validação topológica para geodatabases do ArcMap (itens 1 a 6 da figura 2).

\section{Delimitação de bacias hidrográficas}

Para extrair os limites das bacias hidrográficas, a partir do MDE, as seguintes etapas foram executadas com o ArcMap (extensão Spatial Analyst) em conjunto com a ferramenta ArcHydro (itens 7 a 13 da figura 2):

I. Recortar o MDE com buffer $(1 \mathrm{~km})$ a partir do limite da Ottobacia do Córrego Itapiranga na escala do milionésimo da ANA. O limite do recorte foi editado para que coincidisse com a foz da bacia. Essa etapa é necessária para que o posterior "afundamento" dos vetores no MDE não fosse desfeito, durante a execução da segunda etapa de preenchimento de depressões;

II. Preencher depressões espúrias com a ferramenta Fill Sinks; 
III. Recondicionar o MDE com a ferramenta DEM Reconditioning com os valores: 50 para Sharp, 10 para Smooth e 5 para Buffer. Ao final, a ferramenta Fill Sinks foi novamente aplicada;

IV. Gerar o raster de direção de fluxo com a ferramenta Flow Direction do ArcHydro;

V. Gerar o raster de acumulação de fluxo com a ferramenta Flow Accumulation;

VI. Gerar pontos exutórios (pour points) das bacias. Nesta etapa, optou-se por uma estratégia distinta de Silva et al. (2007), Teixeira (2012) e de Luiz e Faria (2013). Essas referências utilizam as ferramentas Stream Definition e Stream Segmentation para gerar a hidrografia sintética, que definiria o número de bacias hidrográficas delimitadas. Contudo, esse procedimento dificulta a compatibilização da hidrografia sintética com a hidrografia vetorial (real).

Nesta etapa, foi necessário informar ao programa quais são os pontos exutórios, obtidos a partir da hidrografia vetorial, das bacias que se deseja delimitar. Considerando que sempre haverá dois pontos exutórios sobrepostos em cada confluência, os pontos de alguns vértices de montante devem ser deslocados, para que o software possa delimitar duas bacias distintas, uma para cada ponto. Para que fossem gerados os exutórios deslocados, foi executado um código Python no ArcMap, que preenche, na tabela de atributos, as coordenadas UTM do sétimo vértice (para melhores resultados, o vértice escolhido pode variar) de cada segmento de hidrografia, contado a partir do último vértice:

rows $=$ arcpy.UpdateCursor("CAMADA DE HIDROGRAFIA")

for row in rows:

$$
\begin{aligned}
& \text { geom = row.SHAPE } \\
& \text { for part in geom.getPart(): } \\
& \text { for } i \text {, pnt in enumerate(part): } \\
& \text { if } i==\text { part.count }-6 \text { : } \\
& \text { row. } X=\text { pnt. } X \\
& \text { row. } Y=\text { pnt. } Y \\
& \text { rows.updateRow(row) }
\end{aligned}
$$

A partir das coordenadas, foi gerada uma camada de pontos no ArcMap, que serviu de insumo para a ferramenta Snap Pour Point, da extensão Spatial Analyst, com valor de 5 metros para Snap distance, que corresponde ao tamanho do pixel do MDE utilizado.

VII. Gerar os limites das bacias com a ferramenta Watershed. Uma inspeção visual foi realizada para verificar se para todos os trechos de drenagem foram geradas as bacias correspondentes. Os resultados obtidos foram satisfatórios, pois dentre 107 trechos de drenagem, apenas 5 não tiveram suas bacias delimitadas corretamente, devida à má localização de pontos exutórios. Para corrigir os erros remanescentes, os pontos foram editados manualmente, deslocando-os para montante de cada trecho.

VIII. Edição do raster para eliminar ruídos (células isoladas que, ao serem transformadas em polígonos, criam feições não contínuas - multiparte). Isso demandaria trabalho extra de edição e validação topológica das bordas. A ferramenta Boundary Clean mostrou-se eficiente na eliminação de grande parte das células isoladas, utilizando os parâmetros: NO_SORT e TWO_WAY. Para os casos restantes, foram realizadas três aplicações da ferramenta Majority Filter, com as opções: FOUR e HALF, para eliminar células ou grupos de células isoladas. O procedimento permitiu a generalização dos limites entre as bacias e evitou a geração de porções de bacias isoladas do polígono principal.

IX. Transformação do raster de bacias em polígonos vetoriais. Utilizando a ferramenta Raster to Polygon, com a opção Simplify, foram geradas todas as bacias com limites topologicamente consistentes. Sua localização mostrou-se muito próxima dos limites definidos pelo raster original, apesar dos sucessivos processos de generalização (Figura 4). 
Figura 4: Comparação entre os limites finais dos polígonos de bacias (em vermelho) e os do raster original.

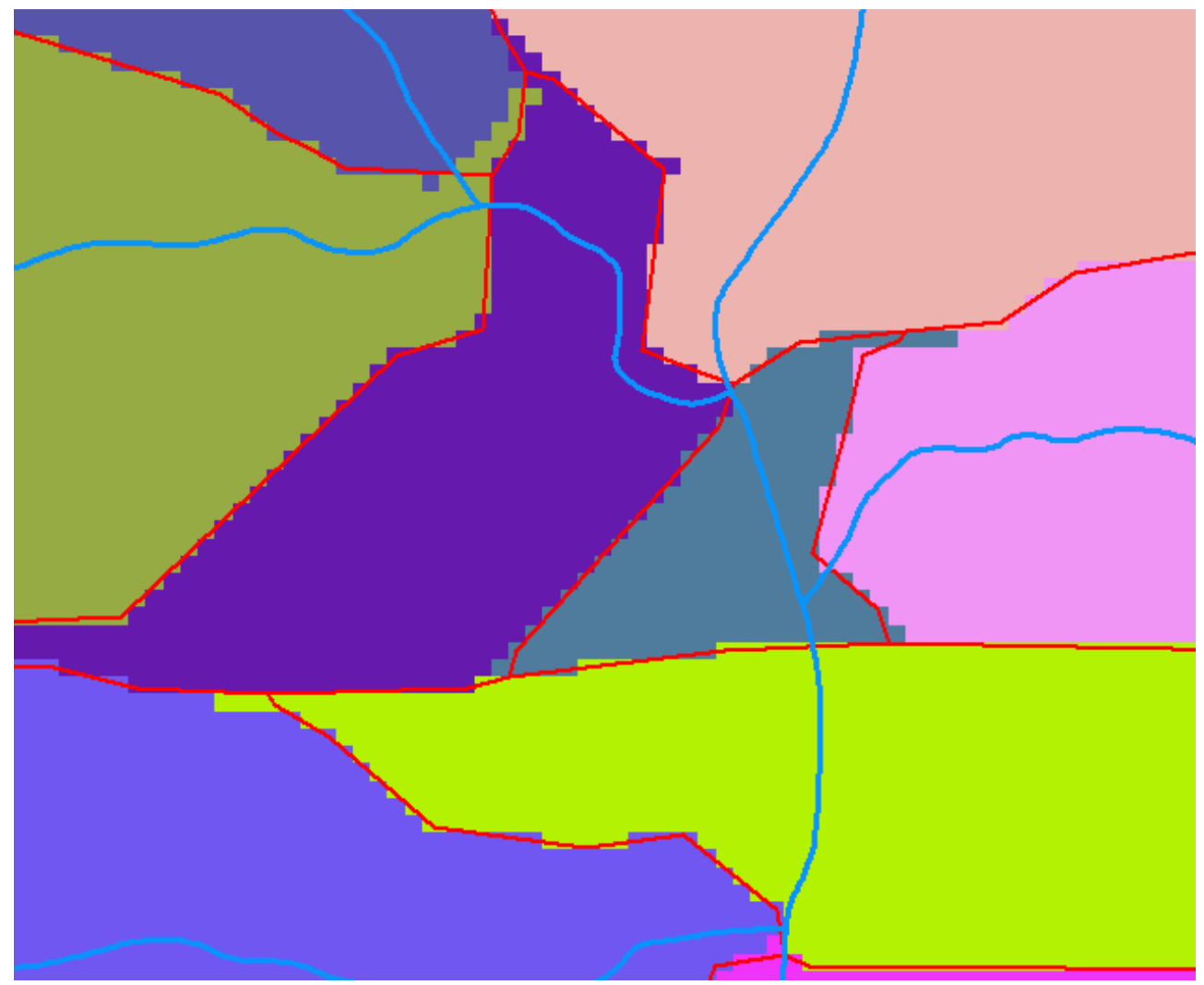

Fonte: Autores

\section{Ottocodificação com pgHydro}

Para as etapas finais de construção da BHO, foi utilizado o banco de dados PostgreSQL 9.3.5, e a extensão espacial PostGIS 2.1.3 (item 14 da figura 2). As instruções SQL do pgHydro Schema (v.2.3.1.10.9) e Tools (v.2.3.1.9.4) foram obtidas no sítio do projeto (http://pghydro.org). O fluxo de trabalho executado foi extraído de Teixeira (2012), com pequenas adaptações:

I. Criar tabelas e funções no banco de dados com o pgHydro Schema. Os vetores da rede de drenagem e bacias foram transformados do formato shapefile para SQL e importados para as tabelas input_drainage e input_catchment, com projeção geográfica UTM e datum SIRGAS 2000. As visualizações somente foram importadas após a execução do passo II, devido ao conflito encontrado entre uma das visualizações e a função de importação dos trechos de drenagem;

II. Criar tabela de trechos de drenagem com o pgHydro Tools, importando os trechos de drenagem conforme a modelagem lógica do banco para a tabela pghgt_drainage_stretch. A partir deste passo, as funções do pgHydro Tools foram executadas individualmente, seguindo a ordem estabelecida pelo arquivo que contém as instruções SQL;

III. Verificar erros de topologia na rede de drenagem com as funções de verificação de trechos múltiplos, não válidos, com autointersecção ou enlace;

IV. Gerar informações de topologia arco-nó. As funções assign_vertex_id e point to id do pgHydro Tools falharam (não geraram a tabela de pontos de drenagem e não atribuíram identificadores às colunas de origem e destino), obrigando a utilização da ferramenta Generate To/From Nodes for Lines do ArcHydro. Os dados gerados nas colunas de origem e destino foram posteriormente importados de volta para a tabela de trechos de drenagem do banco de dados, nas colunas drs_drp_pk_sourcenode e drs_drp_pk_targetnode. A falha nas funções impossibilitou o preenchimento da tabela de pontos de drenagem com os nós da

$\begin{array}{llllll}\text { Caminhos de Geografia } & \text { Uberlândia - MG } & \text { v. 19, n. } 68 & \text { Dez/2018 } & \text { p. 46-60 } & \text { Página } 53\end{array}$


rede (que deveria ser um dos produtos finais da $\mathrm{BHO}$ ), porém não houve prejuízos à continuidade do processo de geração da BHO. Sabendo que as direções de fluxo estavam corretamente representadas de montante para jusante, o campo responsável por essa indicação (drs_bo_flowdirection) foi preenchido manualmente com o valor 1 (ou true, booleano);

V. Criar tabela de bacias, importando as áreas de contribuição hidrográfica com a função pghfn_input_data_catchment_area;

VI. Verificar a topologia das bacias com as funções de verificação de polígonos múltiplos, não válidos, com autossobreposição ou duplicados;

VII. Associar os trechos e as bacias através dos pontos médios dos trechos de drenagem com a função pghfn_AssociateDrainageStretch_CatchmentArea;

VIII. Verificar erros na associação de cardinalidade 1:1 entre trechos e bacias hidrográficas. O relacionamento entre trechos de drenagem e áreas de contribuição hidrográfica possui cardinalidade 1:1 e é do tipo linha EM polígono. Os erros ocorrem, pois nem sempre as extremidades dos trechos de drenagem coincidem com as áreas de contribuição. E a relação deixa de ser 1:1, quando a linha INTERSECTA o polígono. Para resolver o problema, o pgHydro Schema cria uma tabela temporária com os pontos médios dos trechos de drenagem, a partir da qual é feito o relacionamento com as áreas de contribuição hidrográfica através da função pghfn_AssociateDrainageStretch_CatchmentArea;

IX. Calcular os dados nativos primários de comprimento dos trechos de drenagem e das áreas de contribuição hidrográfica. São necessários para o cálculo da codificação de Pfafstetter, pois os códigos são atribuídos considerando a área de montante de cada trecho de drenagem. Foram executadas mais três funções para cada trecho de drenagem: cálculo da área de montante, cálculo do próximo trecho de montante e cálculo do próximo trecho de jusante;

X. Executar Topologia Hídrica: esta etapa dá início ao processo de geração dos códigos de Pfafstetter. A função pghfn_ExportTopologicalTable exporta uma tabela em formato texto chamada AAT.txt, que é utilizada como dado de entrada para o software Topologia Hídrica (v.1.8). Este também exige como dado de entrada o identificador do nó da foz da bacia (neste caso, 105). Depois foi executada a função pghfn_ImportTopologicalTable para importar para o banco de dados as informações da tabela Trechos de Cursos d'Água, gerada pelo Topologia Hídrica;

XI. Gerar informações hidrográficas finais (Ottocodificação) com a execução das seguintes funções: pghfn_Calculate_Pfafstetter_Codification; pghfn_UpdatePfafstetterBasinCode('R'), que substitui o radical $R$ dos códigos Otto pelo código fornecido pelo usuário para a função. Neste caso, foi fornecido o código 8651824 , da bacia do Córrego Itapiranga de nível 7 . As funções pghfn_UpdatePfafstetterWatercourseCode e pghfn_UpdateWatercourse, que são responsáveis por alimentar a tabela de cursos d'água com o código e ordem de cada curso d'água foram executadas. O código de um curso d'água é originário do código da bacia, após a exclusão de todos os algarismos ímpares a partir da direita, até o primeiro algarismo par. A ordem do curso d'água diz respeito ao número de cursos d'água em que ele deverá desaguar até alcançar o oceano, que é obtida contando-se a quantidade de algarismos pares no código do curso d'água.

A última função executada foi pghfn_UpdateWatershedCatchmentArea, que preenche a tabela de feições de bacias hidrográficas com os polígonos das áreas de contribuição hidrográfica, agregados por nível Pfafstetter. Essas bacias (nível Pfafstetter) foram geradas agregando-se as geometrias das áreas de contribuição hidrográfica que possuem códigos idênticos em um determinado nível, que é dado pela quantidade de dígitos no código. Foram geradas bacias de ordem 7 (que corresponde à bacia do Córrego Itapiranga) até a ordem 11.

\section{RESULTADOS E DISCUSSÃO}

Os procedimentos utilizados produziram 107 Ottobacias para a bacia do Córrego Itapiranga (ver Figura 5a). A figura também mostra o limite da bacia na $\mathrm{BHO}$ ao milionésimo (cor vermelha), que revela as diferenças dos contornos causadas pelas distintas escalas. Assim, acredita-se que o

$\begin{array}{llllll}\text { Caminhos de Geografia } & \text { Uberlândia - MG } & \text { v. 19, n. } 68 & \text { Dez/2018 } & \text { p. 46-60 } & \text { Página } 54\end{array}$


MDE mais preciso tenha sido determinante para a delimitação das bacias. O nível Otto máximo atribuído foi onze.

É importante destacar que as BHOs produzidas pela ANA, como as dos rios Doce, Grande e Paranapanema, a partir de bases cartográficas nas escalas 1:50.000 e 1:100.000, atingiram níveis Otto máximos de treze, catorze e quinze, respectivamente. Pondera-se que essa diferença de nível tenha sido ocasionada por um conjunto de fatores, como as distintas escalas, o tamanho das áreas abrangidas por cada base e as diversidades geomorfológicas locais. Considera-se que áreas com maior densidade de drenagem do que o Planalto Ocidental Paulista, e com padrões de drenagem mais ramificados, podem resultar em um maior detalhamento do nível Otto.

Constatou-se a relevância do gerenciamento da bacia com bancos de dados espaciais. Ao trazer funções de consulta da rede hidrográfica para o banco de dados PostgreSQL, o sistema pgHydro possibilitou realizar tarefas recorrentes no processo de tomada de decisão do gerenciamento de recursos hídricos. Como ilustra o exemplo da Figura 5b, é possível responder questões simples, mas importantes, de forma gráfica e textual: quais trechos estão à jusante e à montante de um ponto de interesse (ex.: estação fluviométrica, usuário, obra, entre outros) na rede hidrográfica?

Figura 5: BHO do Córrego Itapiranga - 1:25.000 (a); consulta espacial de trechos de jusante (vermelhos) e de montante (azuis) na rede hidrográfica (b).
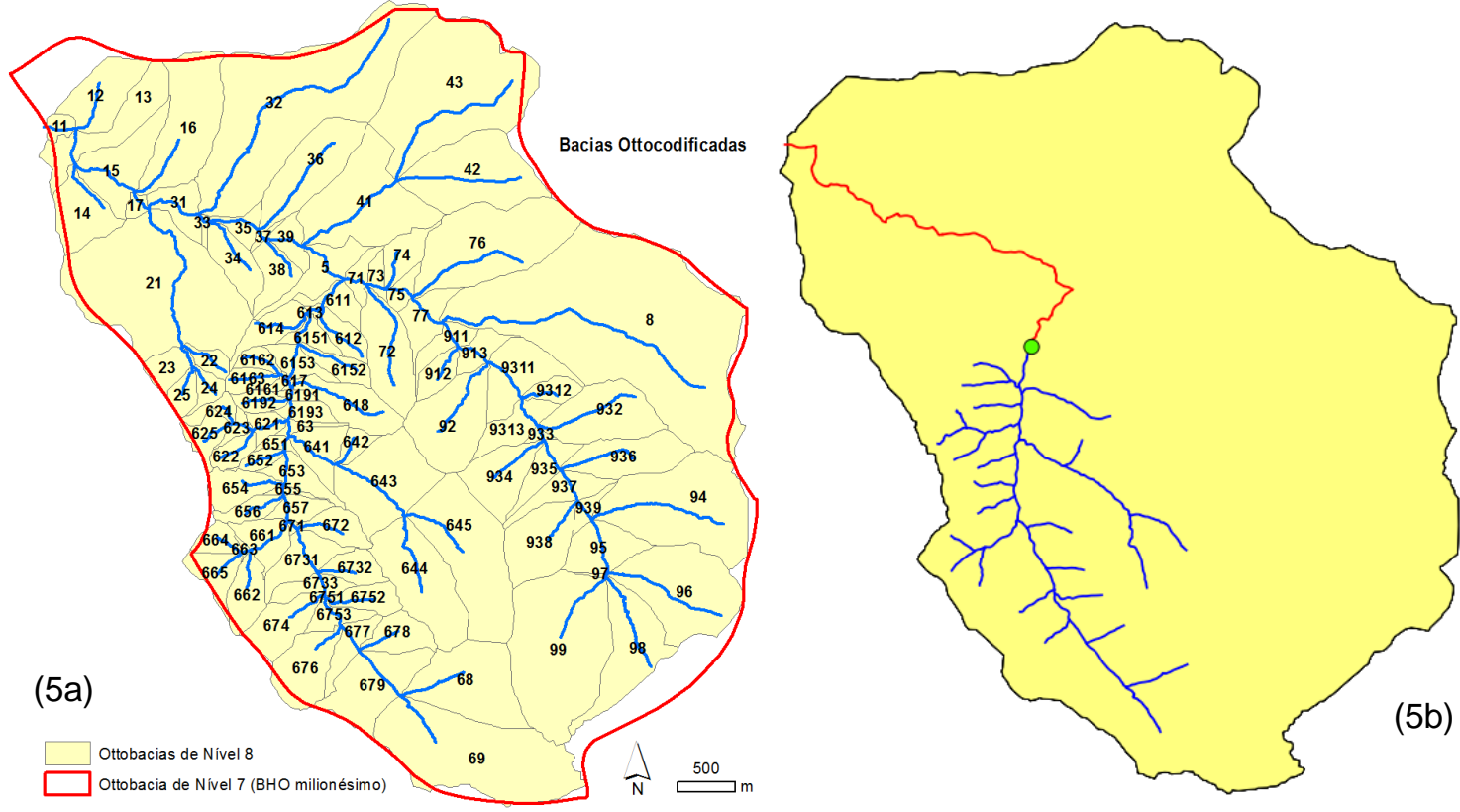

Fonte: Autores

Observou-se também que foi possível conectar o gerenciador de banco de dados do QGIS 2.4 ao PostgreSQL e utilizar as funções do pgHydro Tools pghfn_downstreamstretches(ID) e pghfn_upstreamstretches (ID). Foram utilizadas as instruções SQL abaixo, que permitiram consultar e criar uma camada virtual com as geometrias dos trechos de drenagem de jusante e de montante do ponto de interesse (ex.: ID 87).

Consulta para criar camada de trechos à jusante:

SELECT dws.dws_pk, drs.drs_gm AS dws_gm

FROM pghgt_drainage_stretch drs,

(SELECT pghfn_downstreamstretches(87) AS dws_pk) dws

$\begin{array}{llllll}\text { Caminhos de Geografia } & \text { Uberlândia - MG } & \text { v. 19, n. 68 } & \text { Dez/2018 } & \text { p. 46-60 } & \text { Página } 55\end{array}$


WHERE dws.dws_pk $=$ drs.drs_pk

Consulta para criar camada de trechos à montante:

SELECT ups.ups_pk, drs.drs_gm AS ups_gm

FROM pghgt_drainage_stretch drs,

(SELECT pghfn_upstreamstretches(87) AS ups_pk) ups

WHERE ups.ups_pk = drs.drs_pk

Verificou-se que os dados da rede hidrográfica e do Modelo Digital de Elevação, fornecidos pelo IGC, foram adequados ao processo de Ottocodificação na escala 1:25.000. A edição vetorial dessa rede demandou apenas a união e quebra de alguns trechos. A ferramenta do ArcMap para verificação de valência foi essencial para validação topológica da rede.

Caso o pesquisador opte pelo uso exclusivo de programa livres, recomenda-se seguir o fluxo de trabalho proposto por Teixeira (2012), com validações topológicas executadas pelo banco de dados PostgreSQL e correções efetuadas através do programa QGIS ou similar. Esta opção pode implicar em maior complexidade operacional, mas permitirá realizar a ottocodificação sem os programas comerciais.

A opção adotada neste artigo foi híbrida. Foram utilizados o ArcMap, e sua extensão Spatial Analyst, e o conjunto de ferramentas hidrológicas ArcHydro. O processo demandou alterações no fluxo de trabalho usual, com a criação de pontos exutórios em vértices anteriores aos vértices finais de cada trecho de drenagem e a utilização de ferramentas de generalização do raster, para a delimitação dos polígonos. A metodologia de deslocar os pontos exutórios se mostrou eficiente, pois foram necessárias poucas intervenções manuais (menos de $5 \%$ dos pontos).

Foram constatados problemas na utilização das funções de roteamento, oriundas do pgRouting e aplicadas pelo pgHydro Tools. Com as devidas correções, será possível construir integralmente as BHOs e produzir informações dos pontos de drenagem. As demais funções do pgHydro Tools não apresentaram dificuldades operacionais no estudo de caso.

Quando se considera a estrutura do fluxograma metodológico (figura 2), nota-se que a quantidade e as especificidades do processo de criação da $\mathrm{BHO}$ revelam um significativo nível de complexidade operacional. A simplicidade das consultas espaciais (ex.: Figura $5 b$ ) contrastou com as dificuldades tecnológicas da sua constituição. Mas, ainda que isso possa reduzir a velocidade inicial de construção das bases, os benefícios da ottocodificação mostraram um expressivo potencial para o gerenciamento de recursos hídricos.

Do ponto de vista contextual, e guardadas as devidas proporções, a essência da concepção sistêmica de bacias hidrográficas, expressas nas definições de Coelho Netto (1998) e de Mattos e Perez Filho (2004), pode ser comparada com as características e tendências de desenvolvimento tecnológico institucional: um sistema aberto e complexo, cuja estrutura e organização decorrem das inter-relações dos seus componentes.

A estrutura da codificação hierárquica das bacias hidrográficas de Pfafstetter, uma das suas grandes vantagens, permite sua aplicação em diferentes escalas cartográficas, com maior ou menor detalhamento. Esse processo de codificação está de acordo com as necessidades de descentralização da gestão de dados institucionais brasileiros, cuja premissa é a integração e o compartilhamento. Esse binômio pode ser considerado como símbolo da evolução computacional recente. Também denominado como interoperabilidade, esse provável anglicismo está associado não só aos processos de padronização de dados, mas aos de sistematização de conceitos e termos (QUEIROZ FILHO e GIANNOTTI, 2012).

Além disso, destaca-se que a base hidrográfica vetorial $(1: 25.000)$, cedida pelo Instituto Geográfico e Cartográfico do Estado de São Paulo (IGC), foi construída conforme as normas da Infraestrutura Nacional de Dados Espaciais (INDE). De forma semelhante, constatou-se que os padrões de aquisição e estruturação de dados geográficos do Sistema Nacional de Informações sobre Recursos Hídricos (SNIRH), cujo objetivo é a gestão de recursos hídricos, integram uma Infraestrutura de Dados Espaciais (IDE).

$\begin{array}{llllll}\text { Caminhos de Geografia } & \text { Uberlândia - MG } & \text { v. 19, n. } 68 & \text { Dez/2018 } & \text { p. 46-60 } & \text { Página } 56\end{array}$


As IDEs, definidas como um conjunto de tecnologias, políticas e mecanismos institucionais que facilita o acesso aos dados espaciais (GSDI, 2012, p. 6), podem ser consideradas uma tendência irreversível para administrar e compartilhar os dados espaciais institucionais. Essa estrutura padronizada tornou possível o compartilhamento e a disseminação de dados geográficos via web (NAKAMURA e QUEIROZ FILHO, 2012). Nessa conjuntura, as Agências, os Comitês de Bacias Hidrográficas, além da própria ANA, constituem os nós de uma grande e descentralizada rede, e não só utilizam, mas também tem atribuições para produzir, atualizar e manter os respectivos dados sobre os recursos hídricos, codificados segundo a metodologia Pfafstetter, em distintas escalas cartográficas.

\section{CONSIDERAÇÕES FINAIS}

Uma Base Hidrográfica Ottocodificada, na escala 1:25.000, do Córrego Itapiranga (SP) foi construída com os programas ArcMap, QGIS e o banco de dados PostgreSQL. Nessa bacia de $26 \mathrm{~km}^{2}$, cujo córrego mede $8 \mathrm{~km}$, foram geradas 107 Ottobacias (nível máximo 11). Esses valores, obtidos em escala de detalhe, indicam a magnitude e a dificuldade de gerenciamento dos recursos hídricos em um país de dimensões continentais, como o Brasil.

Apesar de observados problemas nas funções de roteamento (pgRouting), acredita-se que, com pequenas correções, em breve será possível construir integralmente as BHOs e produzir informações dos pontos de drenagem com o sistema pgHydro.

Constatou-se um significativo nível de complexidade operacional no processo de construção das $\mathrm{BHO}$. Contudo, os benefícios das consultas espaciais mostraram um expressivo potencial ao gerenciamento dos recursos hídricos. Além disso, considera-se que essas dificuldades iniciais possam ser interpretadas como inerentes ao atual estágio de desenvolvimento tecnológico, que busca a integração e o compartilhamento de dados.

\section{REFERÊNCIAS}

ANA - Agência Nacional de Águas. Codificação de Bacias Hidrográficas pelo Método de Otto Pfafstetter: Aplicação na ANA. Agência Nacional de Águas, Superintendência de Apoio à Gestão de Recursos Hídricos. Brasília: ANA, SAG, 2012, 46 p.

ANA - Agência Nacional de Águas. Topologia Hídrica: método de construção e modelagem da base hidrográfica para suporte à gestão de recursos hídricos: versão 1.11. / Agência Nacional de Águas, Superintendência de Gestão da Informação. Brasília: ANA, SGI, 2006, 29 p.

BONHAM-CARTER, G. F.; ROGERS, P. J.; ELLWOOD, D. J. Catchment basin analysis applied to surficial geochemical data, Cobequid Highlands, Nova Scotia, Journal of Geochemical

Exploration, v. 29, n. 1, p.259-278, 1987. https://doi.org/10.1016/0375-6742(87)90081-1

BRASIL, Resolução CNRH no 30, de 11 de dezembro de 2002, que define metodologia para codificação de bacias hidrográficas, no âmbito nacional. Diário Oficial da União. Brasília, DF, 19 mar. 2003. Disponível em <http://www.cnrh.gov.br/index.php?option=

com_docman\&task=doc_download\&gid=73>. Acesso em: 10 jan 2017.

CHRISTOFOLETTI, A. (1980). Geomorfologia. São Paulo: Edgard Blucher, 1980, 200 p.

COELHO NETO, A.L. (1998) Hidrologia de encosta na interface com a geomorfologia. In: GUERRA, A. J.T. e CUNHA, S.B. (org) Geomorfologia: uma atualização de bases e conceitos. Bertrand Brasil, Rio de Janeiro, 3 ed.: p. 93.148.

ELBEIH, S. F. An overview of integrated remote sensing and GIS for groundwater mapping in Egypt, Ain Shams. Engineering Journal, v. 6, n. 1, p.1-15, 2015.

https://doi.org/10.1016/j.asej.2014.08.008

ELLUL, C.; HAKLAY, M. Requirements for Topology in 3D GIS. Transactions in GIS, v.10, n.1, p. 157-175, 2006. https://doi.org/10.1111/j.1467-9671.2006.00251.x

FÜRST, J.; HÖRHAN, T. Coding of watershed and river hierarchy to support GIS-based hydrological analyses at different scales. Computers \& Geosciences, v. 35, n. 3, p. 688-696, 2009. https://doi.org/10.1016/i.cageo.2008.04.007

$\begin{array}{llllll}\text { Caminhos de Geografia } & \text { Uberlândia - MG } & \text { v. 19, n. 68 } & \text { Dez/2018 } & \text { p. 46-60 } & \text { Página } 57\end{array}$


GOMES, J. V. P.; BARROS, R. S. A importância das Ottobacias para gestão de recursos hídricos. In: XV Simpósio Brasileiro de Sensoriamento Remoto, 15. (SBSR), 2011. Curitiba, PR. Anais Eletrônicos... São José dos Campos: INPE, 2011, p. 1287-1294.

GSDI - Global Spatial Data Infrastructure Association. The SDI Cookbook. 2012. Disponível em: <http://gsdiassociation.org/images/publications/cookbooks/SDI_Cookbook_from_Wiki_2012_upda te.pdf >. Acesso em: 07 mai 2018.

HORTON, R. E. Erosional development of streams and their drainage basins: hydrophysical approach to quantitative morphology. Geological Society of America Bulletin, v. 56, n. 3, p. 275-370, 1945. Doi: 10.1130/0016-7606.

INSTITUTO GEOGRÁFICO E CARTOGRÁFICO - IGC. Hidrografia da Região Oeste do Estado de São Paulo, escala 1:25.000. (versão preliminar). 2010.

JAGER, A. L.; VOGT, J. V. Development and demonstration of a structured hydrological feature coding system for Europe. Hydrological Sciences Journal, v. 55, n. 5, p.661-675, 2010. https://doi.org/10.1080/02626667.2010.490786

JENSON, S. K. Applications of hydrologic information automatically extracted from digital elevation models. Hydrol. Process, v.5, p. 31-44, 1991. https://doi.org/10.1002/hyp.3360050104

JENSON, S. K. Automated derivation of hydrologic basin characteristics from digital elevation data. Proceedings. Auto-Carto 7, Digital Representations of Spatial Knowledge, Washington, DC, p. 301-310. 1985.

JENSON, S. K.; DOMINGUE, J. O. Extracting topographic structure from digital elevation data for geographic information system analysis. Photogrammetric Engineering and Remote Sensing, v. 54, n. 11, p.1593-1600. 1988.

LINDSAY, J. B. Efficient hybrid breaching-filling sink removal methods for flow path enforcement in digital elevation models. Hydrol. Process. v. 30, n. 6, p. 846-85, 2016.

https://doi.org/10.1002/hyp.10648

LINDSAY, J. B.; CREED, I. F. Removal of artifact depressions from digital elevation models. Hydrol. Process. v. 19, n. 16, p.3113-3126, 2005. https://doi.org/10.1002/hyp.5835

LINDSAY, J. B.; DHUN, K. Modelling surface drainage patterns in altered landscapes using LiDAR. International Journal of Geographical Information Science, v. 29, n. 3, p. 397-411, 2015. https://doi.org/10.1080/13658816.2014.975715

LINDSAY, J. B.; ROTHWELL, J. J.; DAVIES, H. Mapping outlet points used for watershed delineation onto DEM derived stream networks, Water Resour. Res. v. 44, W08442, 2008. https://doi.org/10.1029/2007WR006507

LUIZ, C. H. P.; FARIA, S. D. Construção da base Otto-codificada em Minas Gerais: implementação de metodologia desenvolvida por Otto Pfafstetter (1989) para escalas 1:100.000 e 1:50.000. In: XVI SIMPÓSIO BRASILEIRO DE SENSORIAMENTO REMOTO, 16. (SBSR), 2013. Foz do Iguaçu, PR. Anais eletrônicos... São José dos Campos: INPE, 2013, pp. 2455-2462.

MARTZ, L. W.; GARBRECHT, J. An outlet breaching algorithm for the treatment of closed depressions in a raster DEM, Computers \& Geosciences, v. 25, n. 7, p. 835-844, 1999. https://doi.org/10.1016/S0098-3004(99)00018-7

MATTOS, S.H.V.L.; PEREZ FILHO, A. Complexidade e estabilidade em Sistemas Geomorfológicos: uma introdução ao tema. Revista Brasileira de Geomorfologia. v. 5, n.1, p.1118, 2004. https://doi.org/10.20502/rbg.v5i1.28

NAKAMURA, E. T.; QUEIROZ FILHO, A. P. Infraestrutura de dados espaciais: exemplo do Parque Estadual de Intervales - SP. Revista Brasileira de Cartografia, v. 64, p. 723-735, 2012.

O'CALLAGHAN, J. F.; MARK, D. M. The extraction of drainage networks from digital elevation data. Computer Vision, Graphics, and Image Processing, v. 28, n. 3, p. 323-344, 1984. https://doi.org/10.1016/S0734-189X(84)80011-0

PEUCKER, T.; DOUGLAS, D. Detection of surface-specific points by local parallel processing of digital terrain elevation data. Computer Graphics and Image Processing, v. 4, n. 4, p.375-387, 1975. https://doi.org/10.1016/0146-664X(75)90005-2

\begin{tabular}{llllll}
\hline Caminhos de Geografia & Uberlândia - MG & v. 19, n. 68 & Dez/2018 & p. 46-60 & Página 58
\end{tabular}


PFAFSTETTER, O. Classificação de bacias hidrográficas: metodologia de codificação. Rio de Janeiro, Rio de Janeiro, Brasil: Departamento Nacional de Obras de Saneamento, 1989.

PISSARRA, T. C. T.; RODRIGUES, F. M.; ARRAES, C. L.; GALBIATTI, J. A.; BORGES, M. J. Topographical characteristics and evaluating water quality in watershed management. Ingeniería e Investigación, v. 28, n. 3, p. 87-91, 2008.

QUEIROZ FILHO, A. P.; GIANNOTTI, M. A. Mapas na Web. Revista do Departamento de Geografia, volume especial 30 anos, p. 171-189, 2012. https://doi.org/10.7154/RDG.2012.0112.0010

SANTOS, C. C. P.; SHIRAIWA, S. Padronização de limiares de área acumulada máxima para definição de redes de drenagem através de modelos digitais de elevação em diferentes escalas. Caminhos de Geografia, v. 13, n. 42, p. 228-239, 2012.

SEEMULLER, W. W. The extraction of ordered vector drainage networks from elevation data. Computer Vision, Graphics and Image Processing, v. 47, n.1, p. 45-58, 1989. https://doi.org/10.1016/0734-189X(89)90053-4

SHREVE, R. L. Statistical Law of Stream Numbers. The Journal of Geology, v.74, n.1, p.17-37, 1966. https://doi.org/10.1086/627137

SILVA, C. L.; OLIVEIRA, C. A. S. Runoff measurement and prediction for a watershed under natural vegetation in central Brazil. Rev. Bras. Ciênc. Solo, vol.23, n.3, p. 695-701, 1999. https://doi.org/10.1590/S0100-06831999000300024

SILVA, M. A.; ARAÚJO JÚNIOR, G. J. L. D.; PINTO, M. B. P.; TEIXEIRA, A. A.; PRADO, A.; SCHERER-WARREN, M.; TRIGO, A. J.; BORELLI, A. J. Construção de Base Hidrográfica Ottocodificada: metodologia para delimitação de bacias a partir de modelo digital de elevação: o caso da bacia do rio São Francisco. In: XVII SIMPÓSIO BRASILEIRO DE RECURSOS HÍDRICOS, 17. (SBRH), 2007. São Paulo, SP. Anais eletrônicos... Porto Alegre: ABRH, 2007, 20 p.

SINGH, P.; GUPTA, A.; SINGH, M. Hydrological inferences from watershed analysis for water resource management using remote sensing and GIS techniques, The Egyptian Journal of Remote Sensing and Space Science, v.17, n. 2, December, p.111-121, 2014. https://doi.org/10.1016/i.ejrs.2014.09.003

SOUZA, J. D.; BOGUSZ, J. A.; MAFREI, A.; GERDARHT, C.; COSTA, C. M.; LESSA, G.; BUENO, J. P.; BRENSSEN, M.; MATSUSHIT, M.; HAMERSCHMIDT, P. F. A.; ANDRETTA, R.; NALINI, V. Base Hidrográfica do Estado do Paraná na escala 1:50.000. In: XIX SIMPÓSIO BRASILEIRO DE RECURSOS HÍDRICOS, 19. (SBRH), 2011. Maceió, AL. Anais eletrônicos... Porto Alegre: ABRH, 2011, $12 \mathrm{p}$.

STRAHLER, A. N. Dynamic Basis of Geomorphology. Geological Society of America Bulletin, v. 63, n. 9, p.923-938, 1952. https://doi.org/10.1130/0016-7606(1952)63[923:DBOG]2.0.CO;2

STRAHLER, A. N. Quantitative analysis of watershed geomorphology. Eos Trans. AGU, v. 38, n. 6, p. 913-920, 1957. https://doi.org/10.1029/TR038i006p00913

TEIXEIRA, A. A. Ottocodificação Estendida e Inteligência Hidrográfica em Banco de Dados Geográficos. 2012. 425 f. Tese (Doutorado em Geociências Aplicadas) - Instituto de Geociências, Universidade de Brasília, Brasília, 2012. Disponível em: $<$ http://hdl.handle.net/10482/11181>.

TEIXEIRA, A. A.; SILVA, A. M.; MOLLERI, G. S. F.; FERREIRA, F. V.; BORELLI, A. J. PgHydro Objetos Hidrográficos em Banco de Dados Geográficos. In: XX Simpósio Brasileiro de Recursos Hídricos, 20. (SBRH), 2013. Bento Gonçalves, RS. Anais eletrônicos... Porto Alegre: ABRH, 2013, 8 p.

UZEIKA, T.; MERTEN, G. H.; MINELLA, J. P. G.; MORO, M. Use of the SWAT model for hydrosedimentologic simulation in a small rural watershed. Rev. Bras. Ciênc. Solo, v.36, n.2, p. 557565, 2012. https://doi.org/10.1590/S0100-06832012000200025

VERDIN, K. L.; VERDIN, J.P. A Topological System for Delineation and Codification of the Earth's River Basins. Journal of Hydrology, v. 218, p. 1-12, 1999. https://doi.org/10.1016/S0022$\underline{1694(99) 00011-6}$

\begin{tabular}{llllll}
\hline Caminhos de Geografia & Uberlândia - MG & v. 19, n. 68 & Dez/2018 & p. 46-60 & Página 59
\end{tabular}


VOGT, J. V.; SOILLE, P.; JAGER, A.; RIMAVICIUTE, E.; MEHL, W.; FOISNEAU, S.; BODIS, K.; DUSART, J.; PARACCHINI, M. L.; HAASTRUP, P.; BAMPS, C. A pan-European River and

Catchment Database. Luxembourg: Office for Official Publications of the European Communities, Report EUR 22920 EN. 2007.

Recebido em: 20/10/2017

Aceito para publicação em: 11/05/2018 